\title{
MULHERES EM REVISTAS LITERÁRIAS MINEIRAS: DO MODERNISMO ÀS NEOVANGUARDAS
}

\section{WOMEN IN LITERARY MAGAZINES FROM MINAS GERAIS: FROM MODERNISM TO NEO-AVANT-GARDES}

\author{
Ana Elisa RIBEIRO ${ }^{1}$ \\ Mário Vinícius Ribeiro GONÇALVES ${ }^{2}$
}

\begin{abstract}
Resumo: A partir de consulta realizada, predominantemente, em fontes secundárias, sob uma perspectiva de gênero, apresentaremos um levantamento preliminar da atuação de mulheres em revistas literárias de Minas Gerais, do modernismo dos anos 1920 até as primeiras manifestações neovanguardistas, no fim da década de 1950. Segundo os critérios de recorte estabelecidos para a construção deste objeto, foram considerados para o levantamento trabalhos de qualquer natureza - textos literários, críticos, teóricos, ensaísticos ou jornalísticos, obras visuais, entrevistas, depoimentos etc. -, desde que realizados por mulheres, atuando seja como integrantes do corpo fixo do expediente das revistas ou como colaboradoras ocasionais. Infelizmente, sem surpresa, o levantamento explicita a escassa participação de mulheres em todas as décadas contempladas do séc. XX, seja como escritoras ou como artistas plásticas, tanto em revistas de Belo Horizonte quanto nas do interior do estado; tanto em periódicos de mais longa duração quanto nos de curto fôlego.
\end{abstract}

Palavras-chaves: Revistas Literárias. Escrita Feminina. Mulheres na Literatura. Perspectiva de Gênero. Edição Literária.

\begin{abstract}
From an investigation conducted predominantly in secondary sources, we will present, based on a gender perspective, a preliminary survey of women's participation in literary magazines in the state of Minas Gerais, Brazil, from modernism in the 1920s to the first neo-avant-garde manifestations in the late 1950s. According to the criteria established for the construction of this object, works of any kind were taken into account - literary, critical, theoretical, essayistic or journalistic texts, visual works, interviews, testimonials, etc. -, provided they were authored by women, acting either as permanent members of the staff of the magazines or as occasional collaborators. Unfortunately and unsurprisingly, this survey highlights the scarce participation of women, whether as writers or visual artists, in magazines published in Belo Horizonte as well as publications in other cities of the state; both in longlasting and short-lived periodicals, in all the decades of the $20^{\text {th }}$ century that were contemplated.
\end{abstract}

Keywords: Literary Magazines. Women's Writing. Women in Literature. Gender Perspective. Literary Publishing.

\section{Considerações iniciais}

A socióloga da literatura Gisèle Sapiro (2016), ao traçar um panorama dos estudos da literatura, incluindo a edição, aponta as questões de gênero como um dos elementos mais

\footnotetext{
${ }^{1}$ Professora do Centro Federal de Educação Tecnológica de Minas Gerais (CEFET/MG); doutora em Linguística Aplicada na linha Linguagem e Tecnologia, pela Universidade Federal de Minas Gerais; anadigital@gmail.com

2 Doutorando em Estudos de Linguagens pelo CEFET/MG, mestre em Design Gráfico Multimídia pela École Supérieure d'Art des Pyrénées (ESAP-Pau, França); mariovinicius20@gmail.com
} 
evidentemente importantes e necessários para uma agenda de pesquisas no século XXI. Muito antes da publicação do livro dela, no entanto, entendemos essa necessidade nos estudos de edição na América Latina, em especial no Brasil, a começar por investigações e publicações recuperadas por pesquisadoras como Zahidé $\mathrm{Muzart}^{3}$, na Universidade Federal de Santa Catarina, e Constância Lima Duarte ${ }^{4}$, na Universidade Federal de Minas Gerais.

Hoje em dia, para qualquer país vizinho que se olhe, podemos observar iniciativas de estudos atravessadas pelas questões de gênero, quando não são elas o ponto fulcral de alguma pesquisa. E isso não se dá apenas na academia. Somente a título de exemplo, em maio de 2019, o site Infobae $e^{5}$ divulgou uma matéria em que narrava um episódio ocorrido no México, durante a Bienal de Novela Mario Vargas Llosa, evento e prêmio relevantes que ocorrem em Guadalajara, cidade também conhecida por suas feiras de livros. Segundo a notícia, dezenas de escritores e escritoras latino-americanos produziram e assinaram o que chamaram de um manifesto "contra o machismo literário", em que rechaçavam a participação de um número muito menor de mulheres no evento, assim como em júris e mesas-redondas, generalizando para os eventos culturais na América Latina. No texto, os assinantes se referem ao absurdo de um evento seguir existindo "sem perspectiva de gênero", em pleno século XXI, no auge dos debates sobre a igualdade e o silenciamento de escritoras. Antes disso, no Brasil, em fevereiro de 2019, a campanha Arte + Feminismo Wikipédia, em parceria com a Casa das Rosas, em São Paulo, propôs a Maratona Arte + Feminismo, cujo objetivo era melhorar o conteúdo sobre mulheres na Wikipédia, enciclopédia virtual que padece da falta de verbetes sobre elas, mas também de editoras de conteúdo ${ }^{6}$. No ano anterior, em abril de 2018, um coletivo chamado Assembleia Permanente de Trabalhadoras Feministas do Campo Cultural, Literário e Intelectual, desde a cidade de Buenos Aires, lançou um manifesto, no site da organização Nosotras Proponemos, com dez pontos para "um compromisso ético e solidário em busca da igualdade de espaços, visibilidade e valorização da mulher no campo cultural, literário e intelectual" . Entre os pontos estão a exigência de "representatividade igualitária em todas as

\footnotetext{
${ }^{3}$ Por exemplo, em obras teóricas sobre mulheres escritoras ou na compilação de textos de escritoras do século XIX. Ver Muzart (1999; 2003).

${ }^{4}$ A professora Constância Lima Duarte tem extensa produção sobre mulheres escritoras, tanto em periódicos quanto em livros. Ver, por exemplo, Duarte (2016).

5 "CONTRA EL MACHISMO LITERARIO", la carta que cuestiona la disparidad de género en los eventos culturales. Infobae, 27 maio 2019. Disponível em: <https://www.infobae.com/america/culturaamerica/2019/05/27/contra-el-machismo-literario-la-carta-que-cuestiona-la-disparidad-de-genero-en-loseventos-culturales/>. Acesso em: 22 jul. 2019.

${ }^{6}$ Ver notícia no PublishNews, disponível em: <https://www.publishnews.com.br/materias/2019/02/19/maratonafeminina?fbclid=IwAR3iIBO3rj389DXPtXz60TiszlnMa4KiVtWYX0xz0LXQU8YQs t9h1xHCRo>. Acesso em: 30 ago. 2019.

${ }^{7}$ As traduções de títulos e nomes são nossas.
}

Revista Graphos, vol. 21, n 2, 2019 | UFPB/PPGL | ISSN 1516-1536 
formas de trabalho cultural" e a luta pelo desmonte de práticas machistas e patriarcais, inclusive pelas próprias mulheres.

São apenas três exemplos de ações em relação às mulheres no campo artístico-intelectual, mas que nos fazem pensar que hoje as artistas jovens tenham mais consciência de gênero e das dinâmicas de funcionamento no campo das artes do que antes, ou pelo menos em maior número, assim como provavelmente têm mais recursos e forças para enfrentar o machismo estrutural, sem nos esquecermos de que são herdeiras das lutas travadas anteriormente, em especial pelas quatro ondas do feminismo brasileiro, desde o século XIX, conforme propõe Constância Lima Duarte $(2003)^{8}$, para ficarmos apenas nas nossas conterrâneas.

Focalizando os espaços e suportes de publicação em que mulheres atuaram desde tempos remotos, revistas e jornais estão entre os primeiros. No Brasil, pelo menos desde o século XIX, algumas mulheres dirigiram ou colaboraram com periódicos, tivessem eles caráter literário ou outro. É o que mostram estudos de Duarte (2003; 2016), por exemplo, e consideramos especialmente interessante o chamado da pernambucana Josefina Álvares de Azevedo, no primeiro número de seu A família, periódico de 1888: "Formem grupos e associações, fundem jornais e revistas, levem de vencida os tirocínios acadêmicos, procurem as mais ilustres e felizes, com sua influência, aviventar a campanha em bem da mulher e seus direitos, no Brasil" (AZEVEDO, 1888 apud DUARTE, 2003, p. 157, grifo nosso). A edição foi e ainda é compreendida como uma das ferramentas mais potentes de luta e do espalhamento de ideias, além de ser sempre uma ação política. E diante de achados de pesquisadoras como Constância Lima Duarte, para citar apenas uma pesquisadora pioneira, optamos por nos concentrar nas Minas Gerais do século XX, quando as ondas do feminismo ainda nos chegavam, intermitentemente.

Com base neste ponto de vista, a partir de consulta realizada, predominantemente, em fontes secundárias, apresentaremos um levantamento preliminar da atuação de mulheres em revistas literárias de Minas Gerais, do modernismo dos anos 1920 até as primeiras manifestações neovanguardistas, no fim da década de 1950. Segundo os critérios de recorte estabelecidos para a construção deste objeto, serão considerados para o levantamento trabalhos de qualquer natureza - textos literários, críticos, teóricos, ensaísticos ou jornalísticos, obras visuais, entrevistas, depoimentos etc. - , desde que realizados por mulheres ${ }^{9}$, atuando seja como

\footnotetext{
${ }^{8}$ Uma versão atualizada deste texto é o primeiro capítulo do livro Pensamento feminista brasileiro - formação e contexto, organizado por Heloisa Buarque de Hollanda (Bazar do Tempo, 2019).

${ }^{9}$ A exemplo de Felipe Martins Paros, em seu artigo "Produção de mulheres nas revistas de invenção dos anos 70", interessa-nos mais, neste momento, inventariar quantitativamente o trabalho produzido por mulheres do que adentrar em uma possível qualificação do que sejam obras de ethos "feminino".
} 
integrantes do corpo fixo do expediente das revistas ou como colaboradoras ocasionais. A origem da colaboradora (se nascida ou residente fora de Minas Gerais ou mesmo do Brasil) não estará em questão, mas sim o local de publicação do periódico.

\section{Por que revistas?}

É conveniente explicitar algumas considerações a respeito de nossa escolha por revistas literárias. Em primeiro lugar, expressões como "revista" ou mesmo "periódico" podem ser nebulosas - apesar de a última corresponder exatamente ao adjetivo da qual é derivada e cujo significado é aparentemente preciso. Com efeito, dicionários da língua portuguesa e enciclopédias e glossários específicos ao campo de estudos da comunicação costumam apontar a periodicidade como inerente a essas publicações ${ }^{10}$. Na prática, entretanto, diversas revistas literárias não só não obedeceram a um intervalo de tempo fixo entre o lançamento de cada número, como também existem exemplos daquelas que não ultrapassaram o primeiro número, ocorrência bastante comum entre periódicos de $\operatorname{artes}^{11}$. Diante dessa constatação, Omar Khouri sugere que melhor "seria denominá-las reuniões, obras coletivas, antologias, álbuns, festas etc." (KHOURI, 2004, p. 12), embora não abra mão do termo "revistas", já que "foi justamente por esse nome que tais publicações foram chamadas por seus idealizadores/editores e por seus leitores" (KHOURI, 2004, p. 12). ${ }^{12}$

Parece-nos também válido evocar Ribeiro (2018), quando elenca, compara e contrasta, textual e graficamente, as várias definições de "livro", segundo uma seleção de instituições e especialistas distintos. Em estudo anterior, ainda inédito (GONÇALVES, 2018) ${ }^{13}$ ao

\footnotetext{
${ }^{10}$ É o que verificamos ao consultar os verbetes "revista" e "periódico" tanto no Dicionário online Caldas Aulete quanto na Enciclopédia INTERCOM de comunicação - esta uma obra coletiva e institucional, editada pela Sociedade Brasileira de Estudos Interdisciplinares da Comunicação.

${ }^{11}$ A periodicidade irregular e a vida curta das revistas literárias, no Brasil e no exterior, estão geralmente atreladas a motivos econômicos - também recorrentemente decisivos ao eventual encerramento dessas publicações. Esse aspecto é apontado em diversas obras consultadas durante esta pesquisa, como Revistas na era pós-verso, de Omar Khouri; Post-Digital Print, de Alessandro Ludovico e a apresentação de Pedro Puntoni e Samuel Titan Jr. presente em todos os volumes da caixa Revistas do modernismo 1922-1929: A revista, Estética, Klaxon, Verde, Revista de antropofagia, Terra roxa e outras terras. Cumpre salientar, no entanto, que também existem revistas de número único concebidas como tal. É o caso, por exemplo, da belo-horizontina Nenhum, publicada em 1947; bem como da carioca Navilouca, publicação posterior, de 1974.

12 Apesar de focar nas revistas de poesia de cunho mais experimental e intersemiótico dos anos 1970 a 1990 (as ditas "revistas de invenção", expressão ao que tudo indica cunhada por Paulo Leminski no ensaio "O veneno das revistas da invenção"), Khouri estende essas considerações às revistas literárias anteriores ao recorte de seu estudo, ilustrando o argumento com exemplos que remontam ao modernismo das primeiras décadas do século XX, no Brasil e em Portugal.

${ }^{13}$ GONÇALVES, Mário Vinícius Ribeiro. O livro e as vanguardas (anti)literárias brasileiras: uma poética da refuncionalização. Belo Horizonte: CEFET-MG, 2018. Não publicado, produzido para disciplina.
} Revista Graphos, vol. 21, n 2, 2019 | UFPB/PPGL | ISSN 1516-1536 
visualizarmos a essência do livro enquanto continuum que vai do polo material ao discursivo, ${ }^{14}$ apontamos como, entre os especialistas e instituições recenseados por Ribeiro (2012), a definição da UNESCO, a mais objetiva (e menos maleável) - "Publicação não-periódica impressa de no mínimo 49 páginas, além da capa, publicada no país e disponibilizada ao público" (UNESCO apud RIBEIRO, 2012, p. 334, tradução nossa) ${ }^{15}$-, é a que mais leva em conta critérios predominantemente situados na região material do continuum; ao passo que a definição de Arlindo Machado, a mais abrangente e dilatada - "todo e qualquer dispositivo através do qual uma civilização grava, fixa, memoriza para si e para a posteridade o conjunto de seus conhecimentos, de suas descobertas, de seus sistemas de crenças e os voos de sua imaginação" (2011, p. 162), concentra-se principalmente nos elementos localizados na região discursiva.

Se, de acordo com esses critérios extremos, a periodicidade permanece o fator determinante (embora, na prática, movediço) na distinção entre livros e revistas - já que a definição de Machado (2011, p. 162) poderia muito bem se aplicar também a estas -, algumas precauções são necessárias. Bucksdricker aponta que, a despeito das inegáveis similaridades, "a dinâmica social que engendra livros e revista nem sempre é a mesma" (2018, p. 41). Podemos verificar essa afirmação a partir de dois aspectos inter-relacionados. Em primeiro lugar, para além da mera regularidade na publicação, revistas pressupõem diferentes temporalidades quando comparadas a livros, uma vez que, designadamente, costumam apresentar maior sincronização "com o ritmo cotidiano da vida"16, ao passo que livros são "obras espaçotemporalmente acabadas. Geralmente, assinados por um único sujeito" (BUCKSDRICKER, 2018, p. 42). Este segundo aspecto, embora discutível, parece fundamental ao debate, uma vez que o caráter predominantemente coletivo das revistas é recorrentemente destacado por diversos autores. Como Paulo Leminski, que formula: "Antologias: essa coletivização do aparecer (se não do fazer) corresponde a uma politização, mesmo que não explícita. E a escolha da revista como veículo (mais que um jornal, mas menos que um livro) a uma posição estéticofilosófica [...]" (2012, p. 296). ${ }^{17}$

\footnotetext{
${ }^{14}$ Cf. formulação kantiana retomada por Chartier (2010).

${ }^{15}$ No original: "Non-periodical printed publication of at least 49 pages, exclusive of the cover pages, published in the country and made available to the public." Disponível em: <http://portal.unesco.org/en/ev.phpURL_ID=13068\&URL_DO=DO_TOPIC\&URL_SECTION=201.html >. Acesso em: 20 jul. 2019.

${ }^{16}$ É o que, lançando mão das ideias de Otto Groth, concede a própria Enciclopédia INTERCOM de comunicação ao final do verbete "Periódicos" (2010, p. 919).

${ }^{17}$ O texto de Leminski, como o de Khouri e Bucksdricker citados, tem por objeto as "revistas de invenção" dos anos 1970. Porém, a observação do poeta curitibano não é essencialmente diferente das considerações a esse respeito apontadas por autores que se detiveram mais especificamente nas revistas de vanguarda do início do século Revista Graphos, vol. 21, n² 2, 2019 | UFPB/PPGL | ISSN 1516-1536
} 
Ora, considerando a especificidade da referida politização, característica às revistas literárias, acreditamos estar diante de um terreno fértil para avaliarmos como, em um século marcado por profundas transformações políticas, sociais, econômicas e comportamentais, as mulheres se movimentaram nesses veículos especialmente comprometidos, por natureza, com a urgência de acompanhar tempos de tal maneira cambiantes. É necessário que iniciativas como esta sejam levadas adiante - ainda que em caráter preliminar -, já que, deixando a questão meramente entregue à dinâmica social ainda vigente, a história da atuação masculina, no mesmo contexto, segue sendo narrada - e eles como protagonistas, o que também pode nos levar a concluir, precipitadamente, que, se pouco chega até nós sobre as mulheres nesses veículos, deve ser porque a participação delas foi de fato ínfima ou irrelevante. É com o objetivo de evitar esse tipo de dedução apressada que retomamos Ribeiro:

\begin{abstract}
A escritora é uma figura pública relativamente recente no Brasil. Mesmo que participasse de todos os fluxos e mecanismos que levam um escritor a se transformar em autor legitimado, muitas vezes não alcançavam esse status, sendo apagadas dos cânones e da história por narradores para quem a medida de todas as coisas é masculina. Isso ocorreu a críticos, editores, outros autores, curadores, antologistas, etc. $(2016$, p. 5$)$.
\end{abstract}

Quanto ao recorte temporal aqui adotado, embora as fontes secundárias e o referencial teórico consultados adentrem o século XXI, encerramos nossa apresentação histórica na década de 1960 por razões estratégicas, afinal, é principalmente a partir do fim dos anos 1950 que a edição artística e literária começa a contar, de forma mais recorrente, com recursos alternativos em relação aos imponentes sistemas de impressão até então tradicionais, os quais implicavam significativo custo material, necessidade substancial de espaço e considerável conhecimento prévio quanto à operação da aparelhagem gráfica. Esse modelo começa a ser abalado com a popularização dos primeiros dispositivos de impressão compactos, de simples utilização e baixo custo, principalmente o mimeógrafo ${ }^{18}$ - que vinha se difundindo desde a década de 1930, mas que inicialmente era utilizado sobretudo para a impressão de documentos sindicais, escolares, informativos, políticos etc. (LUDOVICO, 2012, p. 36-38). Nesse contexto, ganham renovado

XX, como Pedro Puntoni e Samuel Titan Jr. na apresentação de Revistas do modernismo 1922-1929: A revista, Estética, Klaxon, Verde, Revista de antropofagia, Terra roxa e outras terras.

18 "Impressora doméstica" avant la lettre, o funcionamento do mimeógrafo baseia-se no princípio do estêncil, obtido a partir da pressão dispersora exercida em uma folha sensível, a qual, após ser preparada, é inserida na máquina rotativa. Esta libera a tinta, que só penetra no papel onde houve dispersão, seja ela causada pela escrita/desenho manuais ou por outros dispositivos como máquinas de escrever. 
fôlego as vozes individuais e coletivas que começam a se fazer ouvir nos circuitos editoriais paralelos da segunda metade do século XX em diante ${ }^{19}$.

Diante dessa constatação, evocamos Walter Benjamin, que já chamava a atenção para como o trabalho historiográfico havia se tornado substancialmente mais difícil a partir do século XVIII, em que as fontes históricas tornam-se "ilimitadas" devido ao fato de a imprensa na Europa, nesse período, assumir enfim uma proporção considerável (2006, p. 508), constituindose em um grande mercado cuja oferta hipertrofiada corresponde à demanda, por sua vez propiciada pela confluência de vários fatores socioeconômicos (CHARTIER, 1994, p. 189). Ora, as novas alternativas editoriais a que nos referimos contribuíram para acelerar ainda mais a multiplicação das fontes historiográficas. Com efeito, para conhecimento, conseguimos levantar um número de 15 revistas literárias publicadas em Minas Gerais dos anos 1920 até os últimos anos da década de 1950. Entre 1960 e 1985, no entanto, foi possível até o momento identificar a publicação de 45 novos periódicos literários no estado. Ou seja, um número três vezes maior, em um intervalo de tempo consideravelmente menor do que o anterior. Tendo isso em vista, acreditamos que os desdobramentos da edição de periódicos literários em Minas Gerais a partir dos anos 1960 mereçam ser tratados com maior exclusividade em ocasião posterior, a fim de não nos desviarmos das especificidades, já suficientemente complexas, de nosso objeto - situado não apenas antes da popularização de importantes modelos editoriais alternativos, mas também das grandes reformas nos costumes e identidades sociais estimuladas, no Ocidente, pelos “novos movimentos sociais" dos anos 1960, sobretudo o feminismo (HALL, 1999 , p. 23-46). ${ }^{20}$

\section{Lidando com periódicos literários do século XX: aspectos e desafios metodológicos}

Como apontado, no atual estágio desta pesquisa, ainda não foi possível consultar diretamente todos os periódicos inventariados. Na realidade, servimo-nos de fontes secundárias para realizar este levantamento, e nos poucos casos em que foi possível ter acesso à

19 Exemplo pioneiro e emblemático de utilização do mimeógrafo para a impressão de uma publicação contracultural é Beatitude, primeira revista do movimento literário beat estadunidense, lançada em 1959. Ainda anterior é a publicação mimeografada, em 1957, de Cadeira de bronze, do carioca Zuca Sardan (Carlos Felipe Saldanha). Já no caso específico de nosso objeto, o recorte temporal aqui proposto é encerrado com a publicação, pelo grupo que posteriormente será denominado Totem - formado inicialmente por Ronaldo Werneck, Aquiles e Joaquim Branco, Plínio Guilherme Filho e Ana Maria Cabral, entre outros -, de O Muro, jornal mimeografado publicado em Cataguases que terá onze edições entre dezembro de 1961 e setembro de 1962 (cf. RIBEIRO FILHO, 2006).

${ }^{20}$ Nessa obra, o feminismo, tanto como crítica teórica quanto como movimento social, é considerado o último e decisivo dos abalos que a concepção iluminista de sujeito centrado vinha sofrendo desde o advento do pensamento marxista. 
integralidade das revistas, isso se deu por meio de edições fac-similares ou de versões digitalizadas encontradas na internet. A despeito da provisoriedade dos dados que apresentaremos a seguir, o que impede que deles sejam extraídas conclusões mais precisas ou generalizações mais amplas, acreditamos já ser possível detectar certos padrões que, apostamos, poderão ser verificados em uma desejável consulta futura a todas as fontes primárias - ou pelo menos à maior parte delas.

Embora esta distinção não tenha se dado de maneira absoluta, algumas das obras consultadas forneceram indicações predominantemente gerais para o levantamento de revistas literárias mineiras, por vezes se limitando à simples menção à existência de alguma publicação. Uma vez compiladas as remissões a uma lista considerável de periódicos, consultamos um segundo grupo de obras, estas majoritariamente caracterizadas por apresentarem informações específicas sobre essas publicações. Certamente, na prática, essa movimentação ocorreu em mão dupla, já que muitas vezes as obras de cunho mais geral continham valiosas informações pontuais, enquanto certas obras de viés mais específico frequentemente acabavam por nos chamar a atenção para a existência de revistas não mencionadas em outras fontes. Naturalmente, dentre a nossa bibliografia há também documentos híbridos, a meio caminho entre a generalidade e a especificidade. Feitas estas considerações, acompanhemos um breve histórico dos periódicos literários em MG, com ênfase nas colaborações de mulheres nessas publicações, para, em seguida, procedermos a uma primeira interpretação dos dados até o presente coletados.

\section{Revistas nas Minas Gerais e o alvorecer do século XX}

\subsection{Simbolismo}

Antes de adentrarmos no recorte proposto, é necessário salientar que as revistas modernistas não foram as primeiras ligadas a grupos específicos de artistas e escritores brasileiros. Nesse sentido, o Simbolismo foi pioneiro. Na passagem do século XIX para o século $\mathrm{XX}$, surgem no Brasil as revistas ligadas a grupos simbolistas, também marcadas pela curta vida. Em Belo Horizonte, três exemplos notáveis são Lotus, com cinco números lançados em 1900; Minas Artística, com quatro números lançados entre 1901 e 1902 - tendo sido o último impresso em Curvelo; e Horus, que, dirigida por Álvaro Viana, líder do grupo simbolista na capital mineira, durou apenas dois números, lançados em 1902. É de extrema importância a menção à escritora diamantinense Mariana Higina, que, além de ter feito parte da rede de poetas simbolistas, trabalhou assiduamente na incipiente imprensa feminista mineira, fundando, em 
1899, com Maria Mercedes Corrêa de Oliveira Mourão, Maria Josefina de Medeiros, Clélia Rabello, Heloisa e Djanira Passos, o jornal Esperança. Parte desse grupo fundará, no ano seguinte, também em Diamantina, o jornal Voz Feminina, nele publicando artigos em que criticavam "a ideologia dominante da inferioridade feminina e defendiam o direito das mulheres à educação e ao voto" (PAGANINI, 2010, p. 247). ${ }^{21}$

\subsection{Modernismo}

Avançando para 1922, animado pela intenção de dar imediata continuidade ao debate das ideias levantadas pela Semana de Arte Moderna, é publicado, em São Paulo, Klaxon: mensário de arte moderna, o primeiro periódico modernista do Brasil, frequentemente considerado o mais graficamente ousado dessa primeira safra de nosso Modernismo. Sua curta e polêmica duração (nove números) e seu modelo de financiamento, pelo próprio grupo de organizadores e colaboradores - dentre eles Guilherme de Almeida, Mário de Andrade, Sérgio Milliet e Oswald de Andrade -, ainda que auxiliados ocasionalmente por anunciantes, ${ }^{22}$ serão reincidentes na trajetória de muitos periódicos modernistas que, de forma rápida e prolífica, o sucederam por todo país. Quanto à participação de mulheres em Klaxon, embora tenha sido pequena, não foi inexistente. Coincidentemente, para o que nos interessa neste estudo, a primeira colaboração feminina na revista paulista foi assinada justamente por uma belo-horizontina: a artista plástica Zina Aita, com ilustração extratexto encartando o número 4. Klaxon, com efeito, foi precursora em outro aspecto: nenhuma mulher cuja atividade artística principal fosse a literatura colaborou no periódico. ${ }^{23}$ As outras três mulheres que, além de Aita, tiveram seus trabalhos impressos na revista foram as artistas plásticas Anita Malfatti e Tarsila do Amaral (aquela, autora da ilustração do encarte do número 5, esta, do encarte do último número) e a pianista Guiomar Novaes, autora de uma resenha literária, no número 5, e de uma crônica sobre cinema, no número 6.

\footnotetext{
${ }^{21}$ Também nesta obra (p. 246) o autor aponta o início do periodismo feminista em Minas Gerais em 1873, com $O$ Sexo Feminino, publicado na cidade de Campanha e fundado por Francisca Senhorinha da Motta Diniz, defensora da emancipação feminina. A tese de Paganini, fundamental para a compreensão do posicionamento dos simbolistas mineiros em relação à modernidade e suas várias implicações, propõe, aproximando-se das considerações finais, uma análise longa e de fôlego dedicada a como os simbolistas mineiros se situaram quanto ao feminismo e às representações da mulher.

${ }^{22}$ A conturbada relação dos editores de Klaxon com seus anunciantes, cuja crônica se deu em público, feita em parte nos textos publicados na própria revista, foi extremamente curiosa, repercutindo nas posteriores dificuldades encontradas pelo grupo para o financiamento da revista. Gênese Andrade dá notícia detalhada a esse respeito em seu ensaio de apresentação à edição fac-similar de todos números de Klaxon, incluída em Revistas do modernismo 1922-1929.

${ }^{23}$ Felipe Martins Paros, no artigo "Produção de mulheres nas 'revistas de invenção' dos anos 70", observará fenômeno semelhante, a começar por Lygia Clark em Navilouca, na qual foi a única colaboradora.
}

Revista Graphos, vol. 21, n 2, 2019| UFPB/PPGL | ISSN 1516-1536 
Em Minas Gerais, a primeira publicação a explorar a trilha modernista aberta por Klaxon foi a belo-horizontina A revista. Dirigida por Martins de Almeida e Carlos Drummond de Andrade e tendo como redatores Emílio Moura e Gregoriano Canedo, A revista contou com três números entre 1925 e 1926, sendo que em nenhum deles foi publicada colaboração de autoria feminina.

Esse cenário muda, ainda que muito timidamente, na revista Verde. Publicada em Cataguases, na Zona da Mata mineira, Verde marca o início da carreira literária dos jovens integrantes do grupo homônimo, dentre os quais Henrique de Resende, Martins Mendes, Rosário Fusco e Guilhermino César, que financiavam a edição da revista com a ajuda de alguns anunciantes e marchands externos, notadamente Mário de Andrade. Contou com seis números, lançados entre 1927 e 1928, e em suas páginas foram publicados trabalhos de apenas duas mulheres, ambas artistas visuais argentinas: Maria Clemencia e Norah Borges. A primeira colaborou com um desenho no número 5 e uma linoleogravura no número seguinte, o primeiro e último de uma anunciada segunda fase da revista, que não vingaria. Nesse número foi igualmente publicado um retrato de Maria Clemencia feito por Norah Borges, integrante do Grupo de Florida, que reunia escritores e artistas visuais argentinos de vanguarda e no qual também transitava Jorge Luis Borges, irmão de Norah. ${ }^{24}$

De volta a Belo Horizonte, no final da década, sob direção de João Dornas Filho, Acquiles Vivacqua e Guilhermino César, é publicado leite criôlo. Tendo contado com 19 números publicados ao longo de 1929 (o primeiro em forma de tabloide e os demais como suplemento dominical do jornal Estado de Minas), leite criôlo estampou poemas de quatro colaboradoras: a paraense Eneida, Thereza Marchetti, Carmem Corrêa de Mello e Mieta Santiago. Quanto a esta, a única

que chegou a publicar dois poemas no suplemento, era também uma conhecida sufragete mineira, sendo a primeira aluna da Faculdade de Direito e a primeira eleitora registrada do estado de Minas Gerais, e publicava com certa regularidade, na imprensa de Belo Horizonte, poemas de um modernismo mais discreto do que o que prevalecia na rede nacional modernista de então (DUARTE, 2011, p. 92). ${ }^{25}$

É importante registrar, ainda que de passagem, a existência de pelo menos duas outras revistas literárias no interior de Minas Gerais, nos anos 1920. Em Ubá, também na Zona da

\footnotetext{
${ }^{24}$ Para maiores informações, recomendamos os ensaios que precedem as edições fac-similares de A revista e Verde incluídas na compilação Revistas do modernismo 1922-1929, assinados respectivamente por Ivan Marques e Júlio Castañon Guimarães.

${ }^{25}$ Nessa dissertação, o autor enfatiza que os poemas de autoria feminina publicados em leite criôlo, além de poucos, no geral partilhavam de temática amoroso-sentimental e eram formalmente mais convencionais, sendo "secundário[s] no corpus da publicação mineira" (p. 92).
}

Revista Graphos, vol. 21, n 2, 2019 | UFPB/PPGL | ISSN 1516-1536 
Mata, foi publicada a revista Montanha, sobre a qual, afora a menção à sua existência, até o momento não encontramos nenhuma outra informação (MARQUES, 2014, p. 12). Já em Itanhandu, no sul do estado, alguns meses antes de Verde, é publicada a Electrica, idealizada pelo poeta carioca Heitor Alves, inicialmente ligado ao grupo da revista Festa. Em 1925, Alves havia se mudado para a região da Serra da Mantiqueira por recomendação médica, para o tratamento de uma tuberculose, e lá se empenhou em situar Itanhandu na cena literária de então. E conseguiu fazê-lo, segundo Humberto Werneck, ao publicar em Electrica não somente poesia, ficção e ensaios, mas também material com assuntos de interesse da comunidade local, como noticiário social e anedotas sobre o cotidiano da cidade. Electrica, que contou com um projeto gráfico arrojado, do qual se encarregava o poeta Heli Menegale, durou dez números, publicados entre maio de 1927 e maio de 1929. Nas fontes consultadas para este estudo, no entanto, não foi possível identificar se na revista foram publicadas colaborações de autoria feminina (WERNECK, 1992, p. 75-77).

\subsection{Anos 1930}

Em nosso levantamento, encontramos referência a somente duas revistas predominantemente literárias lançadas durante a década de 1930, ambas de Belo Horizonte. A primeira delas é Grifo, fundada por Karl Weissmann. Contou com sete números, publicados intermitentemente entre 1937 e 1944, apresentando ensaios, contos e poesias de colaboradores como Mário Casasanta, João Dornas Filho, Godofredo Rangel e João Alphonsus. A segunda é Tentativa, revista de viés cristão da qual foram publicados seis números, entre abril e outubro de 1939. Nela foram estampados poemas e textos relacionados a religião, história, economia e política, assinados por colaboradores como Jair Rebello Horta, João Etienne Filho e Murilo Rubião, entre outros. Não encontramos menção à participação de mulheres nessas duas revistas. $^{26}$

\subsection{Anos 1940}

Nos anos 1940, surge um número mais significativo de revistas literárias em Minas Gerais, sobretudo na capital. No início da década, circulava a belo-horizontina Mensagem, que, dirigida por Guilhermino César e secretariada por João Etienne Filho, teve duas fases,

\footnotetext{
${ }^{26}$ Cf. site da Hemeroteca Histórica, que compõe as Coleções Especiais da Biblioteca Pública Estadual de Minas. Disponível em: 〈http://hemerotecahistoricamg.blogspot.com>.
} 
primeiramente como revista e em seguida, como jornal. Em Mensagem foram publicados autores já então consagrados, como Murilo Mendes, Jorge de Lima e Augusto Frederico Schmidt, porém não encontramos referência à colaboração de mulheres em suas páginas (WERNECK, 1992, p. 114).

A experiência de Edifício, por sua vez, foi mais plural, tanto em seus desdobramentos materiais - era um misto de revista, editora e cooperativa de autores - quanto à atuação de mulheres - embora em número ainda gritantemente inferior ao de homens. Na revista, que durou quatro números, publicados entre janeiro e junho de 1946, foram revelados intelectuais importantes como Francisco Iglésias, Sábato Magaldi, Wilson Figueiredo e Autran Dourado componentes do núcleo da publicação -, além de terem sido publicados poemas, contos e ensaios de autores que já eram célebres, como Carlos Drummond de Andrade, Vinicius de Moraes e Emílio Moura, e também dos "quatro vintanistas": Otto Lara Resende, Hélio Pellegrino, Fernando Sabino e Paulo Mendes Campos. No número 2 de Edifício foram publicados depoimentos de escritores então iniciantes, entre os quais Vanessa Netto e a maranhense Lucy Teixeira (que teve três contos estampados na revista), além de colaboração de Henriqueta Lisboa, naquela altura mais experiente que as demais - seu primeiro livro de poemas, Fogo-fátuo, é de $1925 .{ }^{27}$

Pouco depois de sua participação ativa em Edifício, Hélio Pellegrino idealizaria, juntamente com o arquiteto e historiador Sylvio de Vasconcellos, o número único de Nenhum, revista publicada em 1947, ano do cinquentenário de Belo Horizonte. Com a intenção de reunir artistas, escritores e poetas modernos da capital mineira, Nenhum contou com colaborações dos artistas plásticos Alberto da Veiga Guignard e Franz Weissmann, além de contos, ensaios e poemas de escritores como, por exemplo, Emílio Moura, Fritz Teixeira de Salles, Jacques do Prado Brandão, Murilo Mendes, Murilo Rubião e Otto Lara Resende, além de integrantes do núcleo de autores que estreara em Edifício. Três escritoras tiveram textos publicados em Nenhum: Henriqueta Lisboa, Lucia Machado de Almeida e Zuleica Mello. ${ }^{28}$

Iniciativa de grande interesse é a revista Meia-Pataca, de Cataguases, que, em seus dois números - o primeiro datado de julho de 1948 e o segundo, de junho de 1949 - objetivou dar continuidade à tradição literária cataguasense iniciada em Verde. Segundo pudemos levantar até o momento, trata-se da primeira revista literária mineira, dentro do nosso recorte temporal, a contar com uma mulher não somente como colaboradora, mas como diretora: a poeta Lina

\footnotetext{
${ }^{27}$ A respeito de Edifício, cf. CARMONA (2015, p. 32); SOUZA (1998); WERNECK (1992, p. 114-119).

${ }^{28}$ HEMEROTECA HISTÓRICA. Disponível em: <http://hemerotecahistoricamg.blogspot.com/>. Acesso em: 20 jul. 2019.
} 
Tâmega Peixoto. Em depoimento de 2013, o poeta Francisco Marcelo Cabral, que, juntamente com Lina, fundou a revista, é enfático: "Sem metáforas: Meia-Pataca inteira foi obra da Lina. Edição, diagramação (com umas dicas do Rosário Fusco), secretaria, redação de sueltos e resenhas, enfim, ela estava em todas. Eu fui o bói da redação e fiz algumas resenhas por ordem dela" (CABRAL, 2013, p. 21).

Figura 1 - Página inicial do jornal Meia-Pataca, dirigido por Lina Tâmega Peixoto

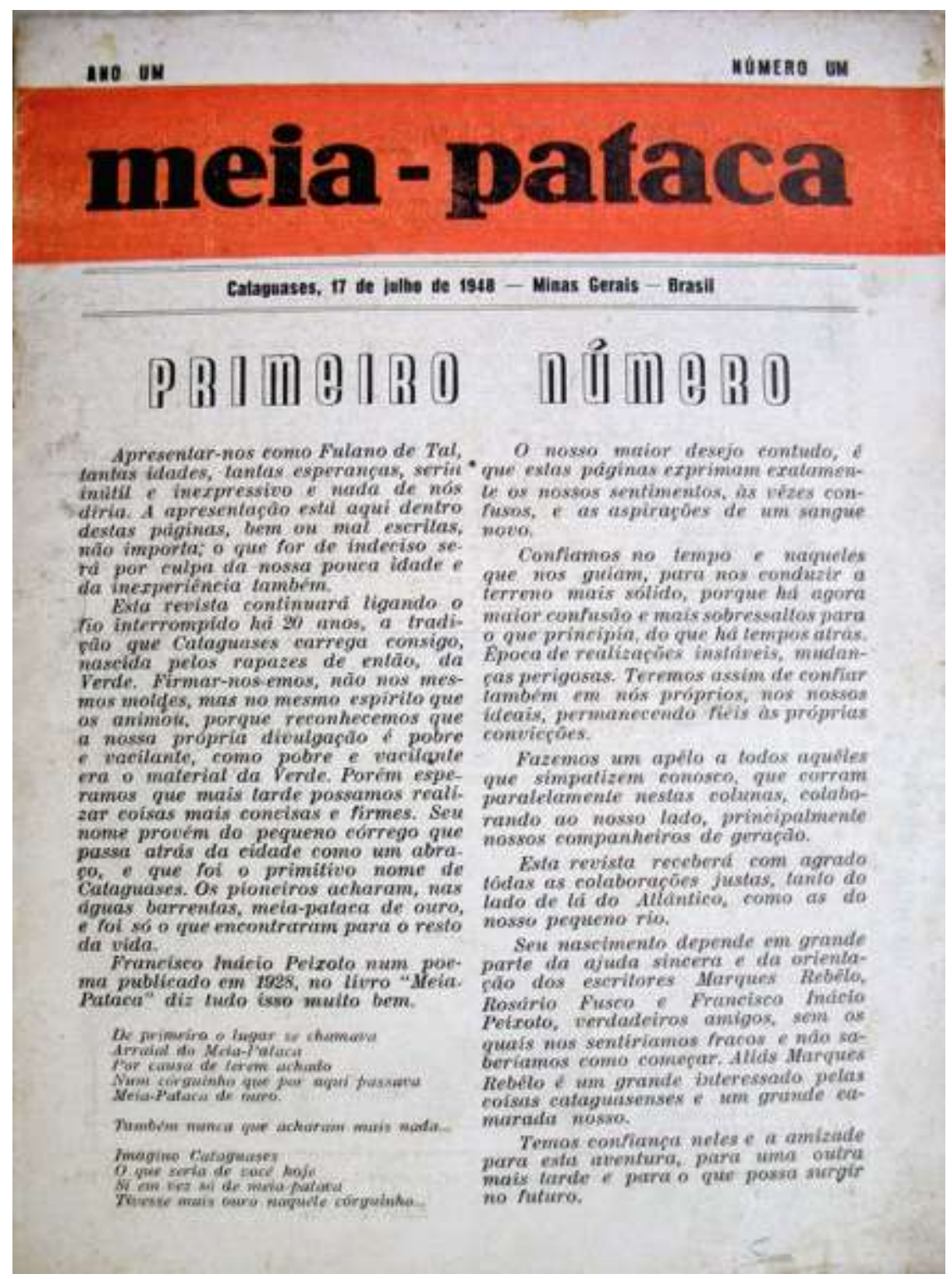

FONTE: 〈http://joaquimbranco.blogspot.com/2007/07/revista-meia-pataca.html〉. Acesso em: 30 ago. 2019. Blog de Joaquim Branco, poeta de Cataguases, participante do grupo literário Totem (anos 1960-1980).

De volta a Belo Horizonte, ainda no final da década, em novembro de 1948, é publicado o primeiro número de Acaiaca, revista mensal criada por Celso Brant. De cunho assumidamente 
tradicionalista e neoparnasiano, a revista existiria até 1960 (WERNECK, 1992, p. 143-144). Não encontramos mais informações sobre a publicação, não tendo sido possível levantar eventual lista de mulheres que nela possam ter colaborado.

\subsection{Anos 1950}

O periodismo literário mineiro abre os anos 1950 de maneira promissora com a revista Vocação, que contou com três números publicados em 1951, em Belo Horizonte. Vocação, assim como Meia-Pataca, foi codirigida por uma mulher: Vera Castro, que dividia o cargo com os outros dois fundadores da publicação, Affonso Ávila e Fábio Lucas. Além do viés literário, em Vocação foram também publicados ensaios sobre cinema e artes plásticas, sinalizando os interesses interdisciplinares do grupo que compunha o periódico. Segundo o que podemos inventariar, nas páginas da revista, além de textos de Vera Castro, foram estampadas colaborações das escritoras Dinah Silveira de Queiroz, Henriqueta Lisboa e Laís Corrêa de Araújo (CARMONA, 2015, p. 23; PAGANINI, 2010, p. 63).

Já na segunda metade da década a capital mineira contará com dois periódicos marcantes: Complemento e Tendência. O primeiro, com quatro números lançados entre 1956 e 1958, foi fundado pelo romancista Ivan Ângelo e pelo poeta e romancista Silviano Santiago, aos quais se juntaram colaboradores de áreas distintas (crítica de cinema, teatro, artes plásticas, música) para compor o caráter destacadamente interdisciplinar da revista. Tivemos acesso a digitalizações dos números 1, 2 e 4 de Complemento, porém não encontramos reproduções do terceiro. No quarto número foram publicadas duas colaborações de autoria feminina: um poema de Mônica Lisboa e um depoimento da poeta Teresinha Alves Pereira. Vale ressaltar que nas páginas finais dos números de Complemento aos quais tivemos acesso são listadas duas mulheres entre os representantes da publicação em outras cidades: Sara Melo (em São Paulo) e Cléa Couto Moreira (em Salvador). ${ }^{29}$

Tendência, por sua vez, assume postura nacionalista e concretista. Dirigida por Fábio Lucas, Rui Mourão e Affonso Ávila - que já haviam atuado em Vocação no início da década e rodada na Imprensa Universitária de Minas Gerais, a revista contou com quatro números, lançados entre 1957 e 1962. Apenas duas mulheres nela colaboraram: Maria Luiza Ramos com um ensaio sobre $O$ romanceiro da inconfidência, de Cecília Meireles, no número 3 (1960), e outro sobre o poema "Ismália", de Alphonsus de Guimaraens, no quarto e último número

\footnotetext{
${ }^{29}$ A respeito de Complemento, cf. CURY (1997); MARQUES (2008); MIRANDA (1998).

Revista Graphos, vol. 21, n² 2, 2019 | UFPB/PPGL | ISSN 1516-1536
} 
(1962) - e Laís Corrêa de Araújo, que no texto "Poesia e situação", publicado no número 4, toma partido de Tendência no calor de uma polêmica envolvendo ataques, na imprensa, entre Rui Mourão e o poeta Mário Chamie, dissidente do concretismo e fundador da poesia práxis (PAGANINI, 2008).

De fato, a transição dos anos 1950 para os anos 1960 é marcada pela afirmação crescente das neovanguardas no panorama artístico e cultural brasileiro, que para isso lutaram contra a resistência de boa parte da cultura dominante literária e acadêmica de então. A poesia concreta é lançada em São Paulo na revista Noigandres, dirigida pelo grupo homônimo formado notadamente pelos irmãos Haroldo e Augusto de Campos e Décio Pignatari. O periódico contou com cinco números publicados entre 1952 e 1962, e foi diretamente seguido por Invenção, que também teve cinco números, publicados entre 1962 e 1967. Em Noigandres não foram publicados textos de autoria feminina, ao passo que Invenção contou com apenas um, publicado em seu quinto e último número: o poema "Meretrilho", da cataguasense Maria do Carmo Ferreira. Logo, apesar de se tratar de publicação paulista, é digno de nota que tenha vindo de uma mineira a única colaboração feminina em veículo concretista durante os anos pertencentes à cronologia oficial do movimento. ${ }^{30}$

Encerrando nossa apresentação histórica, observamos uma das primeiras adesões ao concretismo - além do diálogo estabelecido entre o grupo de Noigandres e o de Tendênciano estado: o Grupo Concreto Mineiro, de Poços de Caldas, atuante de 1957 a 1961, e do qual faziam parte poetas como José Asdrúbal de Amaral, José Pascoal Rossetti e Hugo de Oliveira, entre outros. Embora seus integrantes - todos homens - tenham editado tanto livros individuais quanto coletivos, não chegaram a editar uma revista específica - apesar de terem colaborado, desde 1954, no suplemento Pensamento e Arte, do jornal Folha de Poços (BILHARINHO, 2018, p. 11-48).

O quadro 1 a seguir tem o objetivo de resumir e organizar as informações por nós recolhidas sobre as revistas literárias mineiras de determinadas épocas, em especial focalizando a participação feminina nelas. Tal resumo auxilia na visualização dos dados e da pouca colaboração de poetas e ensaístas mulheres, decorrência, como sabemos, das dificuldades relacionadas à participação no espaço público por artistas que eventualmente existissem; ou pelo simples silenciamento das artistas existentes, mas não suficientemente bem-relacionadas, por exemplo.

\footnotetext{
${ }^{30}$ A respeito de Noigandres e Invenção, cf. COHN (2011); KHOURI (2006). Sobre o poema "Meretrilho", cf. PAROS (2019). 
QUADRO 1 - Resumo das revistas mineiras ao longo do séc. XX e a participação feminina

\begin{tabular}{|c|c|c|c|}
\hline \multicolumn{4}{|l|}{ Década de 1920} \\
\hline Klaxon (SP)* & 1922 & 9 números & $\begin{array}{l}\text { Colaboração da artista plástica mineira Zina } \\
\text { Aita, além de Anitta Malfatti, Tarsila do } \\
\text { Amaral e Guiomar Novaes. }\end{array}$ \\
\hline A revista $(\mathrm{BH})$ & $1925-1926$ & 3 números & Sem participação feminina \\
\hline Verde (Cataguases) & $1927-1928$ & 6 números & $\begin{array}{l}\text { Colaboração das artistas plásticas argentinas } \\
\text { Maria Clementina e Norah Borges }\end{array}$ \\
\hline leite criôlo $(\mathrm{BH})$ & 1929 & 19 números & $\begin{array}{l}\text { Foi suplemento do jornal Estado de Minas. } \\
\text { Colaboração de Eneida (Pará), Thereza } \\
\text { Marchetti, Carmem Corrêa de Mello e Mieta } \\
\text { Santiago }\end{array}$ \\
\hline Montanha (Ubá) & 192- & & Sem mais informações \\
\hline Electrica (Itanhandu) & $1927-1929$ & 10 números & Sem mais informações \\
\hline \multicolumn{4}{|l|}{ Década de 1930} \\
\hline Grifo $(\mathrm{BH})$ & $1937-1944$ & 7 números & Sem mais informações \\
\hline Tentativa $(\mathrm{BH})$ & 1939 & 6 números & Sem mais informações \\
\hline \multicolumn{4}{|l|}{ Década de 1940} \\
\hline Mensagem $(\mathrm{BH})$ & 194- & & Sem mais informações \\
\hline Edificio $(\mathrm{BH})$ & 1946 & 4 números & $\begin{array}{l}\text { Colaboração (n. 2) de Henriqueta Lisboa com } \\
\text { poemas e depoimento, e de depoimentos de } \\
\text { Vanessa Netto e Lucy Teixeira (Maranhão) }\end{array}$ \\
\hline Nenhum (BH) & 1947 & 1 número & $\begin{array}{l}\text { Colaboração de Henriqueta Lisboa, Lucia } \\
\text { Machado de Almeida e Zuleica Mello }\end{array}$ \\
\hline Meia-pataca (Cataguases) & $1948-1949$ & 2 números & $\begin{array}{l}\text { Considera-se a primeira diretora de uma } \\
\text { revista literária: a poeta Lina Tâmega Peixoto }\end{array}$ \\
\hline Acaiaca $(\mathrm{BH})$ & $1948-1960$ & & Sem mais informações \\
\hline \multicolumn{4}{|l|}{ Década de 1950} \\
\hline $\operatorname{Vocação~}(\mathrm{BH})$ & 1951 & 3 números & $\begin{array}{l}\text { Direção de Vera Castro (com Affonso Ávila } \\
\text { e Fábio Lucas). Colaboração de Dinah } \\
\text { Silveira de Queiroz, Henriqueta Lisboa e Laís } \\
\text { Corrêa de Araújo }\end{array}$ \\
\hline Complemento $(\mathrm{BH})$ & $1956-1958$ & 4 números & $\begin{array}{l}\text { Publicação de poema de Mônica Lisboa e } \\
\text { depoimento de Teresinha Alves Pereira. São } \\
\text { listadas duas mulheres como representantes } \\
\text { da revista em outros estados: Sara Melo (SP) } \\
\text { e Cléa Couto Moreira (Salvador) }\end{array}$ \\
\hline Tendência $(\mathrm{BH})$ & $1957-1962$ & 4 números & $\begin{array}{l}\text { Dois ensaios de Maria Luiza Ramos e um } \\
\text { texto opinativo de Laís Corrêa de Araújo }\end{array}$ \\
\hline Invenção $(\mathrm{SP})^{*}$ & $1962-1967$ & 5 números & $\begin{array}{l}\text { Colaboração da mineira Maria do Carmo } \\
\text { Ferreira no último número. }\end{array}$ \\
\hline
\end{tabular}

FONTE: Elaborado pelo autor e pela autora. 
* A inclusão de algumas revistas paulistas dá-se para que possamos apontar a também quase ausência de participação feminina lá ou a colaboração rara de alguma artista mineira.

\section{Considerações finais}

Após inventariar as colaboradoras - apenas quatro - de leite criôlo, Miguel de Ávila Duarte conclui: “Tais presenças femininas provam, ao contrário, a esmagadora presença de escritores homens, não apenas em leite criôlo, mas no modernismo brasileiro como um todo naquele momento" (DUARTE, 2011, p. 92-93). Infelizmente, segundo o que pudemos levantar, tais constatações podem ser prontamente estendidas aos demais periódicos literários mineiros publicados nas décadas subsequentes à primeira explosão modernista nos anos 1920, não sendo fundamentalmente abaladas até a aurora das neovanguardas, na década de 1950, e seus primeiros desdobramentos no início do decênio seguinte.

A consideração dos três periódicos da década de 1920 aos quais tivemos acesso em detalhes (seja por fontes secundárias minuciosas ou por edições fac-similares de todos os números) enseja uma tríplice problemática, cujos sintomas, acreditamos, merecem ser mais detidamente analisados em ocasião futura: a ausência total de mulheres (em A revista), a publicação somente de artistas plásticas em veículo predominantemente literário (em Verde) e a publicação de textos de autoria feminina cuja temática e linguagem são marcadamente mais convencionais em relação àqueles publicados por homens no mesmo periódico (caso de leite criôlo) (DUARTE, 2011, p. 92).

Embora no geral tenhamos tido acesso a poucos detalhes sobre os dois periódicos literários mineiros iniciados na década de 1930 que pudemos identificar, o que não nos permite afirmar se neles houve efetiva colaboração feminina, podemos, não obstante, afirmar que essa situação se repetiu em relação a todos os periódicos da década anterior e posteriores, sobre os quais também encontramos apenas algumas poucas notícias: na imensa maioria desses casos, ao menos os nomes dos homens que neles atuaram são citados (com exceção do periódico Montanha, publicado em Ubá nos anos 1920 e sobre o qual não encontramos nenhuma outra informação). Em situação alguma chegamos a nos indagar se em determinada revista não teria havido nenhuma colaboração de autoria masculina, ao passo que a dúvida inversa é recorrente em todas as décadas consideradas, o que só muda de figura a partir dos anos 1950, sobre os quais todas as fontes secundárias consultadas não deixam mais de indicar as colaboradoras dos periódicos em questão. 
Os únicos exemplos levantados de revistas literárias mineiras codirigidas e cofundadas por mulheres - Meia-Pataca e Vocação - configuram exceções que, embora legitimamente honrosas, devido ao enorme desequilíbrio entre representação feminina e masculina no meio literário em que se inserem, acabam por ressaltar a nada honrosa desigualdade que já vinha permeando esse meio - sabemos - muito tempo antes do período contemplado no recorte temporal aqui adotado.

Antes de encerrarmos esta apresentação, achamos pertinente evocar as advertências que Ana Elisa Ribeiro dirige às escritoras do século XXI:

\footnotetext{
A escritora de hoje talvez esteja também consciente do caminho que faz, até porque as discussões sobre a violência simbólica estão, mais do que nunca, acesas. No entanto, considero o diálogo com o passado necessário para um melhor posicionamento sobre a atualidade e os esforços empreendidos por antecessoras que, se não contarem com suas sucessoras poetas, professoras, editoras, antologistas e tradutoras, ainda poderão ser apagadas das narrativas futuras, sobre um passado ainda fugidio (2016, p. 8-9).
}

Esperamos que o que nos foi possível inventariar neste estudo, apesar das limitações inerentes à sua própria condição preliminar e à natureza da maior parte das fontes consultadas, possa servir como ponto de apoio para pesquisas futuras, dinamizando-as. Esperamos igualmente que, ao optarmos por documentar os obstáculos com os quais nos deparamos ao longo desta investigação, possamos facilitar sua eventual superação. Por fim, idealizamos tempos em que o saldo de todo e qualquer tipo de violência simbólica perpetrada ao longo da história possa ser devidamente reparado - embora saibamos que para isso há um enorme trabalho pela frente.

\section{Referências}

BENJAMIN, Walter. Teoria do conhecimento, teoria do progresso. In: . Passagens. Belo Horizonte: Editora UFMG; São Paulo: Imprensa Oficial do Estado de São Paulo, 2006. p. $499-530$.

BILHARINHO, Guido (org.). Movimentos poéticos do interior de Minas Gerais. Revista Dimensão Edições, Uberaba, v. 3, 2018.

BUCKSDRICKER, Jorge Alberto Silva. A revista como prática artística nos anos 1970: um debate. Revista Concinnitas, v. 1, n. 30, p. 36-52, 2018.

CABRAL, Francisco Marcelo. Meia-Pataca: quem se lembra? Suplemento Literário de Minas Gerais: a modernidade perene de Cataguases. Número organizado por Ronaldo Werneck. Belo Horizonte, Secretaria de Estado de Cultura, nov. 2013. Edição especial, p. 21 22. 
CARMONA, Kaio Carvalho. 26 poetas ontem: Belo Horizonte literária. 2015. 219 f. Tese (Doutorado em Literatura Brasileira) - Faculdade de Letras, Universidade Federal de Minas Gerais, Belo Horizonte, 2015.

CHARTIER, Roger. Do códice ao monitor: a trajetória do escrito. Estudos avançados, São Paulo, v. 8, n. 21, p. 185-199, 1994.

CHARTIER, Roger. Escutar os mortos com os olhos. Estudos avançados, São Paulo, v. 24, n. 69, p. 6-30, 2010.

COHN, Sergio. Revistas de invenção: 100 revistas de cultura do modernismo ao século XXI. Rio de Janeiro: Beco do Azougue, 2011.

“CONTRA EL MACHISMO LITERARIO”, la carta que cuestiona la disparidad de género en los eventos culturales. Infobae, 27 maio 2019. Disponível em:

<https://www.infobae.com/america/cultura-america/2019/05/27/contra-el-machismo-literariola-carta-que-cuestiona-la-disparidad-de-genero-en-los-eventos-culturales/>. Acesso em: 22 jul. 2019.

CURY, Maria Zilda Ferreira. Complemento: uma geração em revista. Varia Historia, Belo Horizonte, n. 18, p. 241-269, set. 1997.

DUARTE, Constância Lima. Feminismo e literatura no Brasil. Revista Estudos Avançados, v. 17, n. 49, p. 151-172, 2003.

DUARTE, Constância Lima. Imprensa feminina e feminista no Brasil. Século XIX. Belo Horizonte: Autêntica, 2016.

DUARTE, Miguel de Ávila. Leite criôlo: da rede modernista nacional à memória monumental do modernismo. 2011. 224 f. Dissertação (Mestrado em Teoria da Literatura) Faculdade de Letras, Universidade Federal de Minas Gerais, Belo Horizonte, 2011.

GUIMARÃES, Júlio Castanõn. Verde: uma revista e arredores. In: PUNTONI, Pedro; TITAN JUNIOR, Samuel (org.). Revistas do modernismo 1922-1929: A revista, Estética, Klaxon, Verde, Revista de antropofagia, Terra roxa e outras terras. São Paulo: Imprensa Oficial do Estado de São Paulo; Biblioteca Brasiliana Guita e José Mindlin, 2014. Verde: edição facsimilar, p. 11-27.

HALL, Stuart. A identidade cultural na pós-modernidade. Trad. Tomaz Tadeu da Silva e Guacira Lopes Louro. 3 ed. Rio de Janeiro: DP\&A, 1999.

HEMEROTECA HISTÓRICA. Compõe as Coleções Especiais da Biblioteca Pública Estadual de Minas Gerais. Disponível em: 〈http://hemerotecahistoricamg.blogspot.com/>. Acesso em: 04 jul. 2019.

KHOURI, Omar. Noigandres e Invenção: revistas porta-vozes da Poesia Concreta. FACOM, n. 16 , p. $20-33,2^{\circ}$ sem. 2006.

KHOURI, Omar. Revistas na era pós-verso: revistas experimentais e edições autônomas de poemas no Brasil, dos anos 70 aos 90. Cotia: Ateliê Editorial, 2004. 
LEMINSKI, Paulo. O veneno das revistas da invenção. In: Ensaios e anseios crípticos. 2 ed. ampliada. Campinas: Editora da Unicamp, 2012. p. 293-297.

LUDOVICO, Alessandro. Post-Digital Print: The Mutation of Publishing since 1894. Eindhoven: Onomatopee 77, 2012.

MACHADO, Arlindo. Pré-cinemas \& pós-cinemas. Campina: Papirus, 2011.

MARQUES, Fabrício. Afetos da memória, memórias do afeto. Aletria, Belo Horizonte, v. 18, p. 121-134, jul./dez. 2008.

MARQUES, Ivan. Modernismo à mineira. In: PUNTONI, Pedro; TITAN JUNIOR, Samuel (org.). Revistas do modernismo 1922-1929: A revista, Estética, Klaxon, Verde, Revista de antropofagia, Terra roxa e outras terras. São Paulo: Imprensa Oficial do Estado de São Paulo; Biblioteca Brasiliana Guita e José Mindlin, 2014. A revista: edição fac-similar, p. 11-26.

MIRANDA, Wander Melo. Silviano Santiago e a geração Complemento. Scripta, Belo Horizonte, v. 1, n. 2, p. 23-27, $1^{\text {o }}$ sem. 1998.

MUZART, Zahidé Lupinacci. Escritoras brasileiras do século XIX: antologia, volume 1. Florianópolis: Mulheres, 1999.

MUZART, Zahidé Lupinacci. Uma espiada na imprensa das mulheres no século XIX. Estudos Feministas, v. 11, n. 1, p. 225-233, jan./jun., 2003.

NOSOTRAS PROPONEMOS. Nosotras proponemos literatura. Buenos Aires, abr. 2018. Disponível em: 〈http://nosotrasproponemos.org/np-literatura/>. Acesso em: 23 jul. 2019.

PAGANINI, Luiz Antônio. Os simbolistas mineiros e o drama da modernidade. 2010. 313 f. Tese (Doutorado em Estudos Literários) - Faculdade de Letras, Universidade Federal de Minas Gerais, Belo Horizonte, 2010.

PAGANINI, Nilze. Revista Tendência: à procura de uma tradição, à procura do novo. 2008. 254 f. Tese (Doutorado em Letras - Literaturas de Língua Portuguesa) - Pontifícia Universidade Católica de Minas Gerais, 2008.

PAROS, Felipe Martins. Produção de mulheres nas "revistas de invenção" dos anos 70. Arte \& Ensaios, v. 23, p. 95-101, 2018.

PAROS, Felipe Martins. Seguindo o Meretrilho: sobre um poema de Maria do Carmo Ferreira. In: QUEIROZ, João Paulo (ed.). Dez anos depois: o X Congresso CSO’ 2019. Lisboa: Centro de Investigação e Estudos em Belas-Artes (CIEBA); Faculdade de BelasArtes; Universidade de Lisboa; Sociedade Nacional de Belas Artes (SNBA), 2019. p. 419426.

PERIÓDICO. In: DICIONÁRIO Online Caldas Aulete. Disponível em: <http://www.aulete.com.br/periódico/>. Acesso em: 02 jul. 2019.

PERIÓDICOS. In: ENCICLOPÉDIA INTERCOM de Comunicação. São Paulo: Sociedade Brasileira de Estudos Interdisciplinares da Comunicação, 2010. p. 918-919. 
PUNTONI, Pedro; TITAN JUNIOR, Samuel (org.). Revistas do modernismo 1922-1929: A revista, Estética, Klaxon, Verde, Revista de antropofagia, Terra roxa e outras terras. São Paulo: Imprensa Oficial do Estado de São Paulo; Biblioteca Brasiliana Guita e José Mindlin, 2014.

REVISTA. In: DICIONÁRIO Online Caldas Aulete. Disponível em: <http://www.aulete.com.br/revista/>. Acesso em: 02 jul. 2019.

REVISTAS. In: ENCICLOPÉDIA INTERCOM de Comunicação. São Paulo: Sociedade Brasileira de Estudos Interdisciplinares da Comunicação, 2010. p. 1083.

RIBEIRO FILHO, Joaquim Branco. Uma província com o selo da poesia: a trajetória do grupo literário “Totem”, de Cataguases e o experimentalismo das décadas de 1960 e 70. 2006. 219 f. Tese (Doutorado em Literatura Comparada) - Instituto de Letras, Universidade do Estado do Rio de Janeiro, 2006.

RIBEIRO, Ana Elisa. Edição e legitimação literária: vestígios em cartas de escritoras mineiras do século XX. In: XVI Encontro dos Grupos de Pesquisa em Comunicação do XXXIX Congresso Brasileiro de Ciências da Comunicação, 2016, São Paulo. Anais... São Paulo: Intercom, 2016. v. 1. p. 1-15.

RIBEIRO, Ana Elisa. O que é e o que não é um livro: materialidades e processos editoriais. In: RIBEIRO, Ana Elisa. Livro. Edição e tecnologias no século XXI. Belo Horizonte: Moinhos/Contafios, 2018.

SAPIRO, Gisèle. La sociología de la literatura. Ciudad Autónoma de Buenos Aires: Fondo de Cultura Económica, 2016.

SOUZA, Eneida Maria de. Edifício: que geração é essa? Scripta, Belo Horizonte, v. 1, n. 2, p. 13-22, $1^{\text {o }}$ sem. 1998.

UNESCO. Recommendation concerning the International Standardization of Statistics Relating to Book Production and Periodicals. Disponível em:

$<$ http://portal.unesco.org/en/ev.php-

URL_ID=13068\&URL_DO=DO_TOPIC\&URL_SECTION=201.html> . Acesso em: $14 \mathrm{dez}$. 2018.

WERNECK, Humberto. O desatino da rapaziada: jornalistas e escritores em Minas Gerais. São Paulo: Companhia das Letras, 1992. 